\title{
Glass/Polypropylene commingled yarns for damage tolerant thermoplastic composites ${ }^{\S}$
}

\author{
Erdem Selver ${ }^{1 *}$ and Prasad Potluri² \\ 'Department of Textile Engineering, Kahramanmaraş Sütçü Imam University, 46100, Turkey. \\ ${ }^{2}$ North West Composites Centre, University of Manchester, Manchester M13 9PL, UK
}

\begin{abstract}
This work presents manufacturing of glass/polypropylene commingled yarns and analysis of low velocity impact (15J, 25J, and 35J) and compression after impact (CAI) performance of thermoset and thermoplastic composites produced from the hybrid commingled yarns. Hybrid commingled yarns were produced through an air jet nozzle at different air pressures. Results showed that commingled yarn tenacity and mixture quality were highly affected by changing the air pressures. Impact tests indicated that thermoplastic composites absorbed around $73-80 \%$ of the impact energy while thermoset composites absorbed $39-41 \%$. CAI tests presented that thermoplastic composite had higher residual strength with a different failure mechanism under compressive loading.
\end{abstract}

Keywords: Hybrid yarns, fibre reinforced composites, thermoplastic composites, impact and damage tolerance

\section{INTRODUCTION}

There is an increasing trend to use thermoplastic composites due to their high damage tolerance, energy absorption capability and strain rates compared to thermoset composites [1,2]. Although thermoplastic composites have many advantages, their high resin viscosity is a major concern to fill pores at tightly woven or unidirectional textile preforms during manufacturing of composites. Using hybrid-commingled yarns is one of the methods to overcome this problem to manufacture uniform and well impregnated thermoplastic composites [3-7]. Homogenous distribution of matrix and reinforcement fibres reduce mass transfer distances [8] and provide short cycle time compare to long processing cycles of some thermoset matrices $[9,10]$. Thermoplastic composites are manufactured by melting of the matrix part of the commingled yarns under required heat and pressure. During the process, matrix fibres start to melt by reaching of their melting temperature. Once matrix was molten, they fill the gaps between fibres and layers and process continues until full impregnation and consolidation is achieved [11].

It is very common to use glass fibres and thermoplastic polymers (resin, film or fibre forms) as reinforcement and matrix part, respectively during thermoplastic composites manufacturing [12-16]. Some of the previous research showed that thermoplastic matrix composites had higher compression and compression after impact (CAI) properties with high strain values compared to epoxy based composite structures [17, 18]. Vieille et al. [19] observed that using thermoplastic matrices (PPS or PEEK) reduced delamination areas under impact loading compared to epoxy based thermoset composites. Lagattu and Lafarie-Frenot [20] produced carbon/peek thermoplastic and carbon/epoxy thermoset composites to investigate their tensile and open hole tensile behaviour. Their results showed that tensile strength values of thermoplastic composites for plain samples were higher compared to epoxy based samples. However, thermoplastic samples were more sensitive to notching and results were very similar for the open hole samples. Erkendirci and Haque [21] analyzed impact behaviour of S-glass/HDPE, E-glass/HDPE and S-glass/epoxy composite samples. Results indicated that thermoplastic composites have lower stiffness, lower peak forces, higher deflection, lower energy dissipation and lower damage area compared to thermoset samples due to visco-elastic behaviour of the HDPE resin. Waviness makes negative effect on compression behaviour of the composites [22]. Thermoplastic composite can delay delamination propagation which caused by local buckling [23].

The purpose of this work is to investigate glass/PP commingling yarn-processing method and convert these commingled yarns into thermoplastic composites using optimum process parameters. Impact and compression after impact (CAI) performance of glass/PP thermoplastic (GPPT) composites are also compared with glass/PP/epoxy (GPP) and glass/ epoxy (GE) thermoset composites that were analysed in previous work [24]. To date, a number of studies have compa-

\footnotetext{
${ }^{*}$ Corresponding authour

Email: elselver@ksu.edu.tr (E. Selver)

$\S$ This paper was presented in the IMSEC-2016
} 
red impact and damage tolerance of thermoset and thermoplastic composites. However, far too little attention has been paid to investigate the effect of commingled yarns on damage tolerance of both thermoplastic and thermoset composites. Thus, the findings will make an important contribution to the field of hybrid composites containing thermoset or thermoplastic matrices.

\section{EXPERIMENTAL}

S-glass/polypropylene commingled yarns were produced with an air nozzle shown in Figure 1 . The air jet has different orifice angles $\left(0^{\circ}\right.$ and $\left.45^{\circ}\right)$ to create the mixing effect. Air pressure was kept between 1-4 bars while the yarns passing through the nozzle. Overfeeding $(7 \%)$ was used in order to create a low yarn tension inside the nozzle for opening the fibre bundles. Glass and PP volume fractions were 63 and 37\%, respectively in the final commingled yarns.

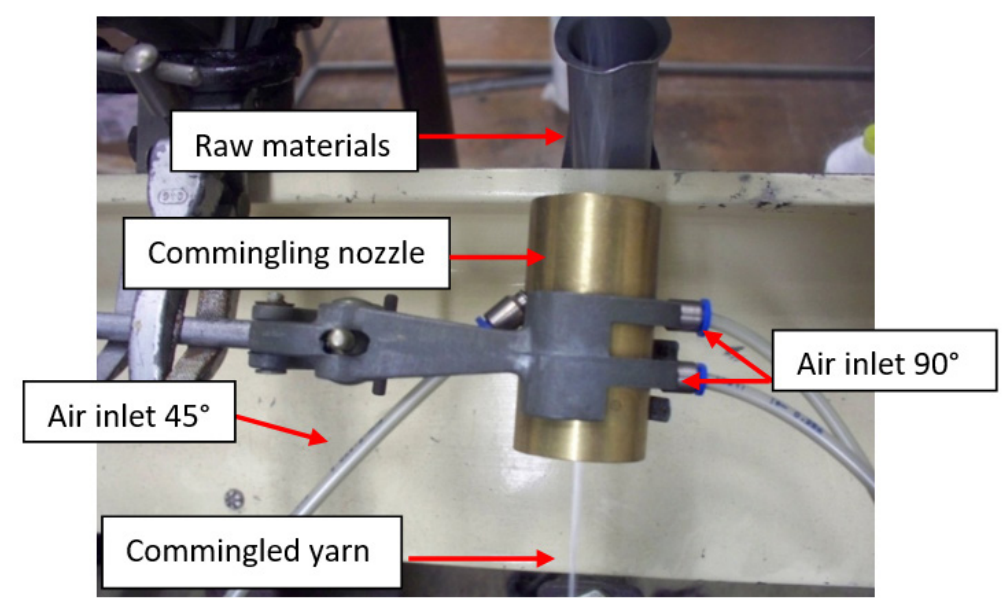

Figure 1 Commingling nozzle.

Once the commingled yarns were produced, they were placed on a frame using a tow placement machine with non-crimp $[0,90]_{4}$ configuration preform as seen in Figure 2. The yarn density is 8 yarns per $\mathrm{cm}$ along the frame. Once the placement finished, the preform was placed in a hot press with a heating and cooling cycles shown in Figure 3.

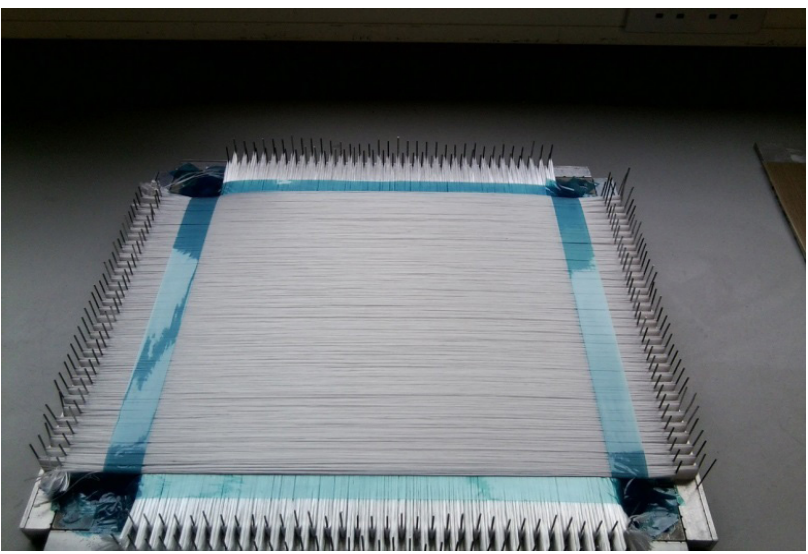

Figure 2 Placement of yarns at [90-0 $]_{4}$ configuration

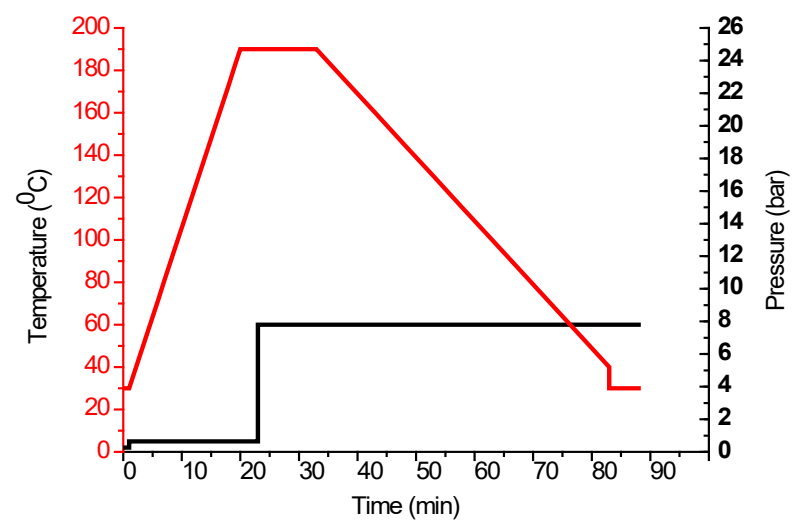

Figure 3 Manufacturing cycle of glass/PP coomposite 
Same non-crimp hybrid preforms (with and without polypropylene fibres) were also used to produce thermoset composites to compare with the thermoplastic composites in terms of impact and compression after impact performance as shown in Table 1 . Hybrid preforms were infused with epoxy resin and hardener mixture using vacuum bagging method at the required temperature and time $\left(8\right.$ hours at $\left.80^{\circ} \mathrm{C}\right)$.

Table 1 Composite Sample Properties

\begin{tabular}{|c|c|c|c|c|c|}
\hline Samples & Fibre & Matrix & Density $(\mathrm{g} / \mathrm{cm} 3)$ & Thickness $(\mathrm{mm})$ & Glass $\%$ Vf \\
\hline GPPT & Glass fibre & PP & 1.85 & 4.04 & 60.1 \\
\hline GE & Glass fibre & Epoxy & 1.93 & 3.17 & 59.0 \\
\hline GPP & Glass and PP & Epoxy & 1.55 & 3.62 & 34.9 \\
\hline
\end{tabular}

\section{TEST METHODS}

Yarn tensile tests were performed according to the ASTM D2256-02 standard with $250 \mathrm{~mm}$ gauge length under crosshead speed of $200 \mathrm{~mm} / \mathrm{min}$. Composite samples were subjected to low impact energies (15 J, $25 \mathrm{~J}$, and $35 \mathrm{~J}$ ) using a CEAST 9350 drop-weight impact test machine. The impacted samples were subsequently tested with INSTRON 5989 testing machine for the evaluation of compression and CAI performance of the laminates. Four specimens were used for each impact and CAI tests.

SEM images were taken with Hitachi S3000N electron microscope to evaluate void fraction and fibre distribution of the samples. Fibre and composite samples were ground in order to have clearer images using 4001200 PC silicon carbide waterproof abrasive papers. Then, diamond pastes were applied on the $6 \mu \mathrm{m}$ and $1 \mu \mathrm{m}$ polishing papers, respectively before polishing of the samples. Density and volume fraction of composites were calculated in accordance with ASTM D792 - 08 and BS EN ISO 1172:1999 standards.

\section{RESULTS AND DISCUSSIONS}

\subsection{Yarn test results}

Figure 4 presents average tensile test results of five commingled yarns specimens at different air pressures. It can be seen that tensile strength decreases with increasing air pressures. The highest strength was achieved when the air pressure is 1 bar. Figure 5 also shows that yarns are bound together at the compact nip regions. These nips are necessary in order to keep un-mingling during non-crimp preform manufacturing. It can also be seen that there is some fibre misalignment and there are glass fibre breakages due to the aggressive action of the compressed air. These broken glass fibres may decrease the strength of the hybrid yarns as observed in Figure 4.

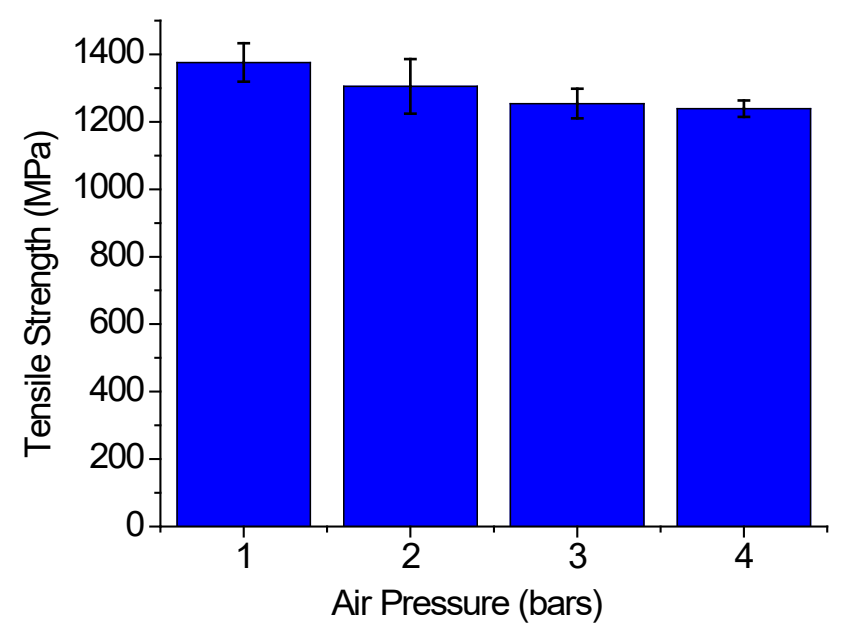

Figure 4 Tensile strength of commingled yarns at different air pressures. 


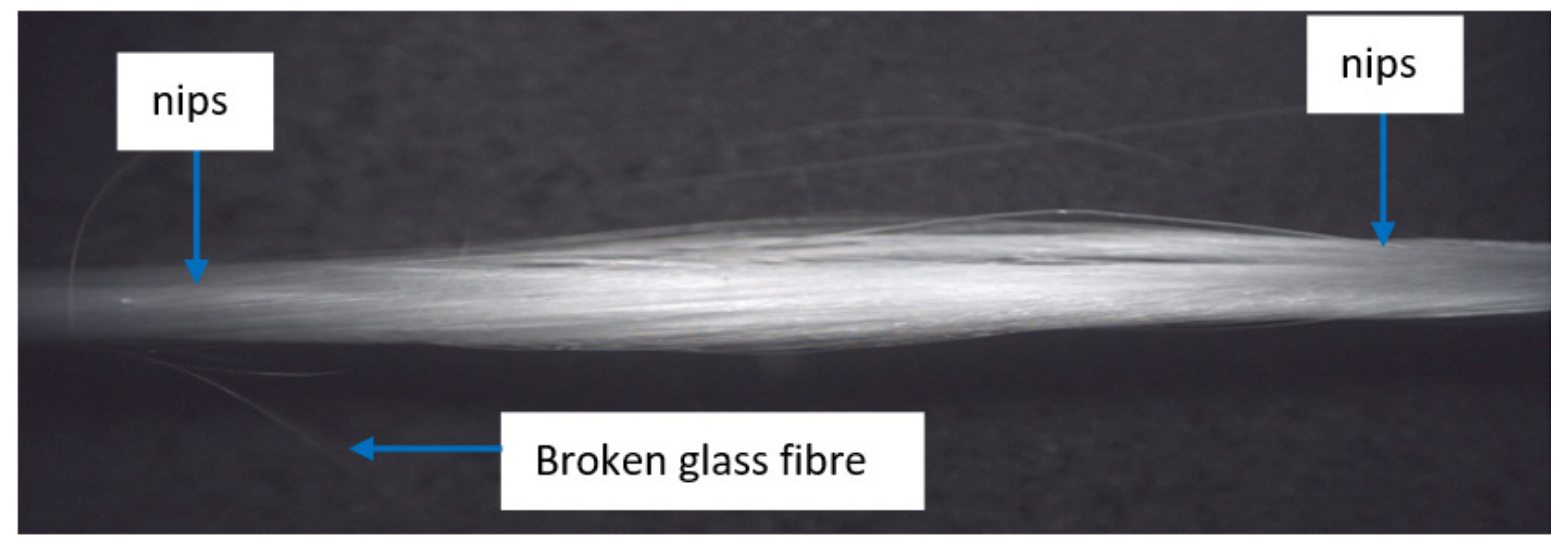

Figure 5 Glass/PP commingled yarn

Figure 6 shows cross-section images of commingled yarns at different air pressures. It indicates that better glass/ PP mixture is achieved when the pressure is higher (Figure 6c). However, 4 bars showed the lowest tensile strength values as in Figure 4. This clears that optimum pressure should be decided to produce the commingled yarns for the composite preforms, since high-pressure decreases strength of the commingled yarns due to broken glass fibres. Therefore, commingled yarns that were produced at 2 bars pressure were used in composite preform fabrics.

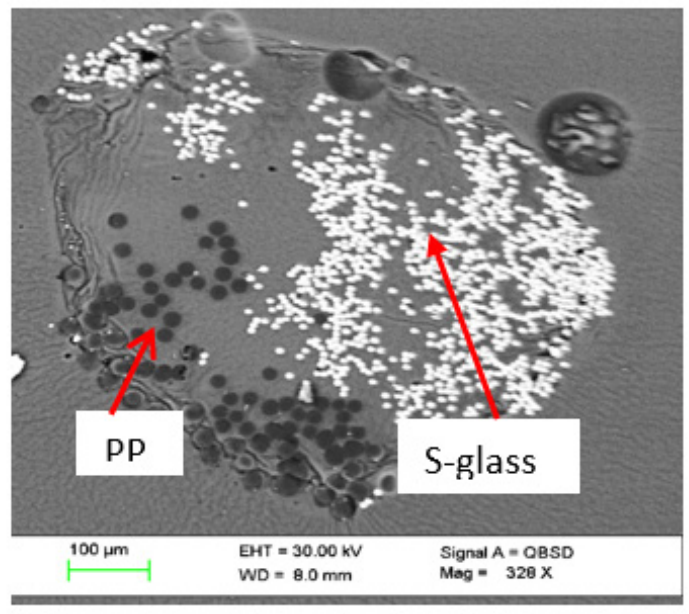

(a)

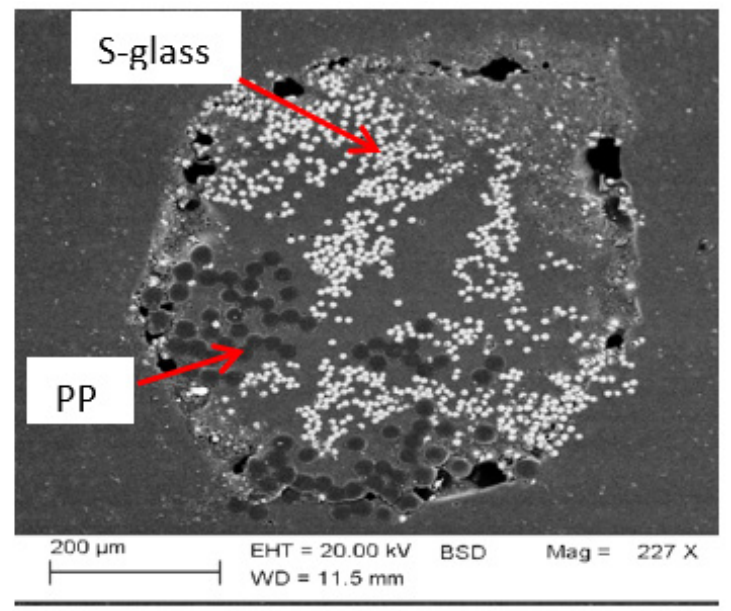

(b)

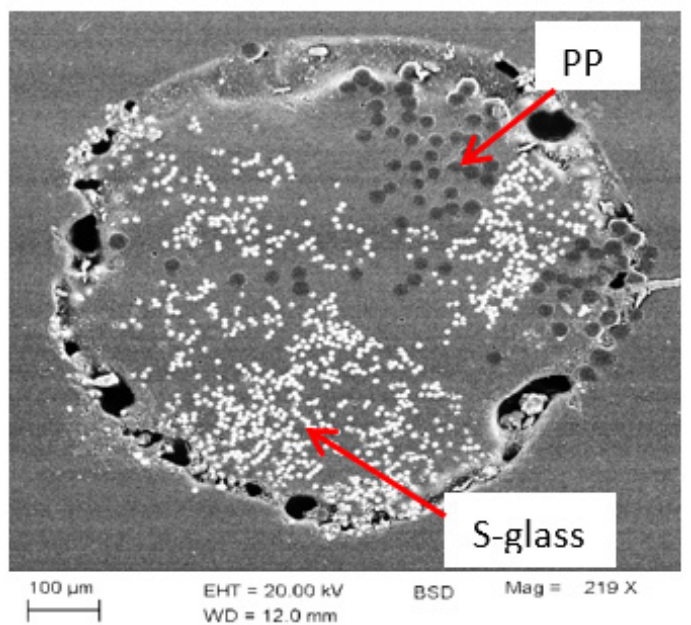

(c)

Figure 6 SEM cross-sectional images of glass/PP commingled yarns after applying: a) 1 bar, b) 2 bars, and c) 4 bars air pressure (The white and black fibres are glass and PP, respectively). 


\subsection{Void Content measurements}

Cross-section images were taken through different layers of the composite samples. Then, these images were used in Datinf Measure software in order to measure void areas using equation (1);

$$
\operatorname{Void}(\%)=\left(\frac{\text { Total void area }}{\text { Total composite area }}\right) \times 100
$$

Layers closer to the mould surface may have less void content compared to middle layers, therefore; void ratios in different layers was investigated in order to understand whether there are any differences between the layers. The structure has eight layers with $[0,90]$ configuration (Fig. 7 ) and the images were taken from the $2^{\text {th }}, 4^{\text {th }}, 6^{\text {th }}$ and $8^{\text {th }}$ layer of the sample in order to have more accurate void values.

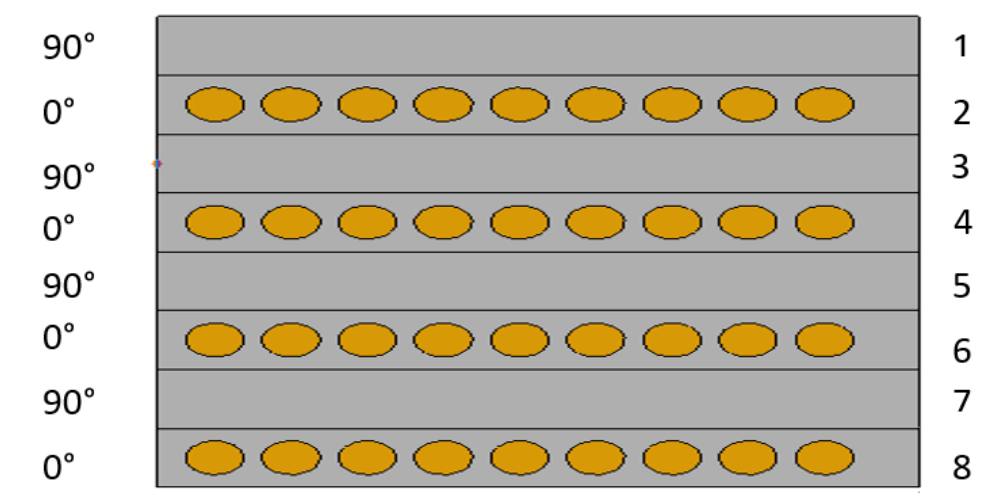

Figure 7 Cross-ply composite with [90-0]4 configuration

Figure 8 presents cross-section images glass/PP composite taken by SEM microscope. Total and void areas of composite part were calculated as in Figure 8a and 8b, respectively. Table 3 presents void content of the different layers of thermoplastic composites. It can be seen that the layer $\left(4^{\text {th }}\right)$ near the middle region had the highest void content compared to other regions while the $8^{\text {th }}$ layer had the lowest void. A possible explanation for this might be that the $8^{\text {th }}$ layer has better thermal contact with the hot press and melting of PP fibres are more efficient. However, heat transfer and melting may not be as good as the contact regions in the middle layers of the composite. This result is very encouraging since all the layers have very low void contents, showing that the impregnation quality of the composite is quite high.

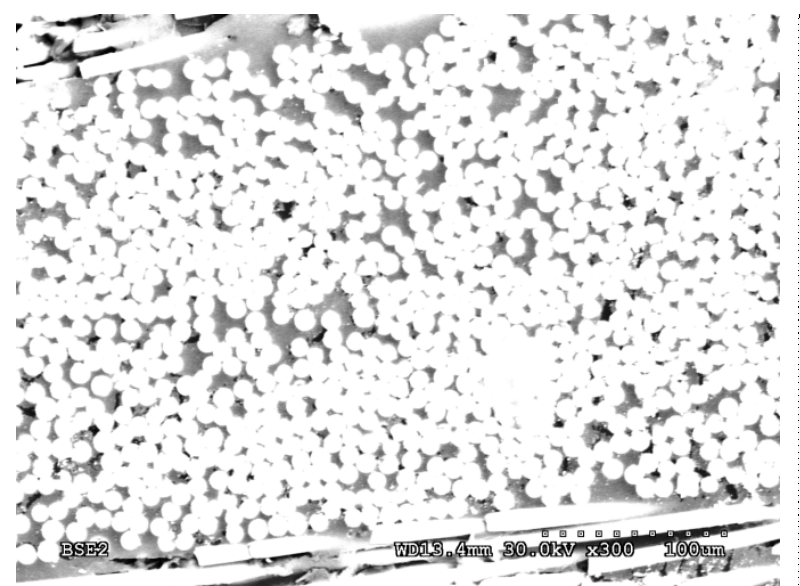

a)

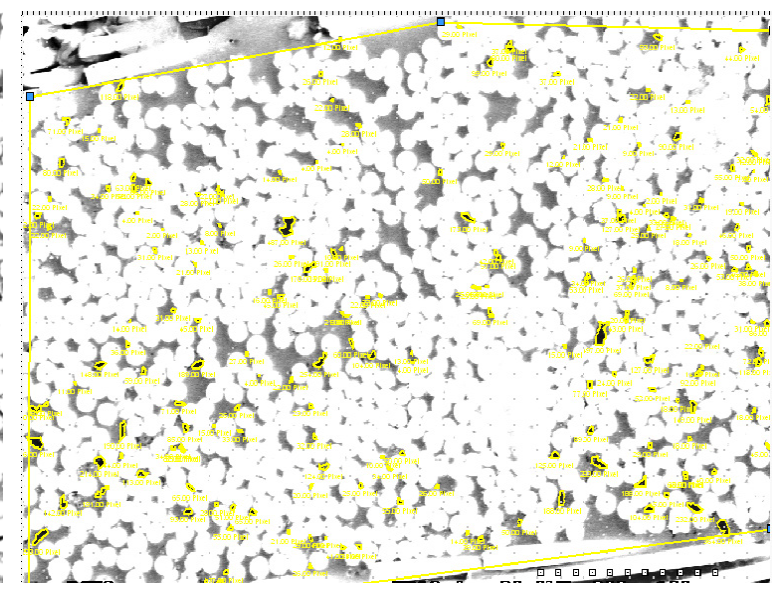

b)

Figure 8 SEM images of composite cross-section: a) before and b) after using the software (yellow marks indicates the void areas)

Table 3 Void content of the thermoset composite in different layers

\begin{tabular}{|c|c|}
\hline Composite layer & Void $(\%)$ \\
\hline $2^{\text {th }}$ & $1.02( \pm 0.15)$ \\
\hline $4^{\text {th }}$ & $1.15( \pm 0.11)$ \\
\hline $6^{\text {th }}$ & $1.05( \pm 0.09)$ \\
\hline $8^{\text {th }}$ & $0.85( \pm 0.23)$ \\
\hline
\end{tabular}


Optimum process parameters were decided after tensile, imaging and void content test results while the commingled yarns should be processed at 2 bars pressure with $7 \%$ overfeeding ratio.

\subsection{Low Velocity Impact tests}

Figures 9-12 presents low impact velocity test results of composite laminates. Figure 9 shows that thermoplastic sample (GPPT) absorbed more energy than the other two thermoset samples [24] at all energy levels. Impact energy is mainly absorbed via damage modes (matrix cracks, delamination, and fibre breakages) and elastic energy (rebounding of the impactor) during low velocity impacts. Figure 10 presents that thermoplastic composite absorbed around $73-80 \%$ of the impact energies while thermoset composites absorbed 39-41 for GE and 49-50\% for GPP samples. This indicates that energy absorption increases with PP content while thermoset GPP composite also contains PP fibres. Similar results were achieved when thermoplastic fibres were added in to thermoset composites [25]. Higher energy absorption is due to plastic deformation and ductile properties of thermoplastic materials.
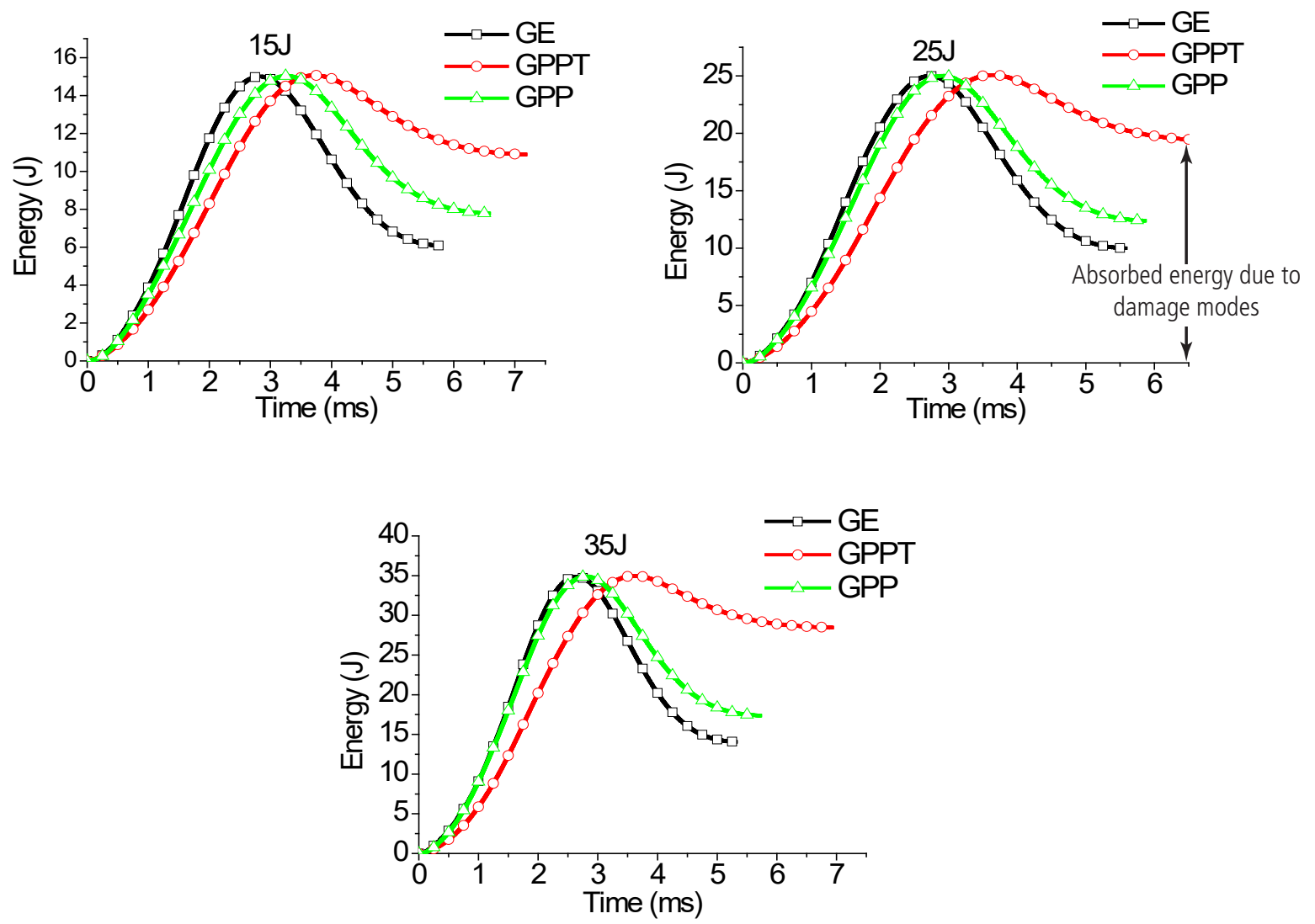

Figure 9 Energy-time history of the samples at different impact energy levels (15-35J)

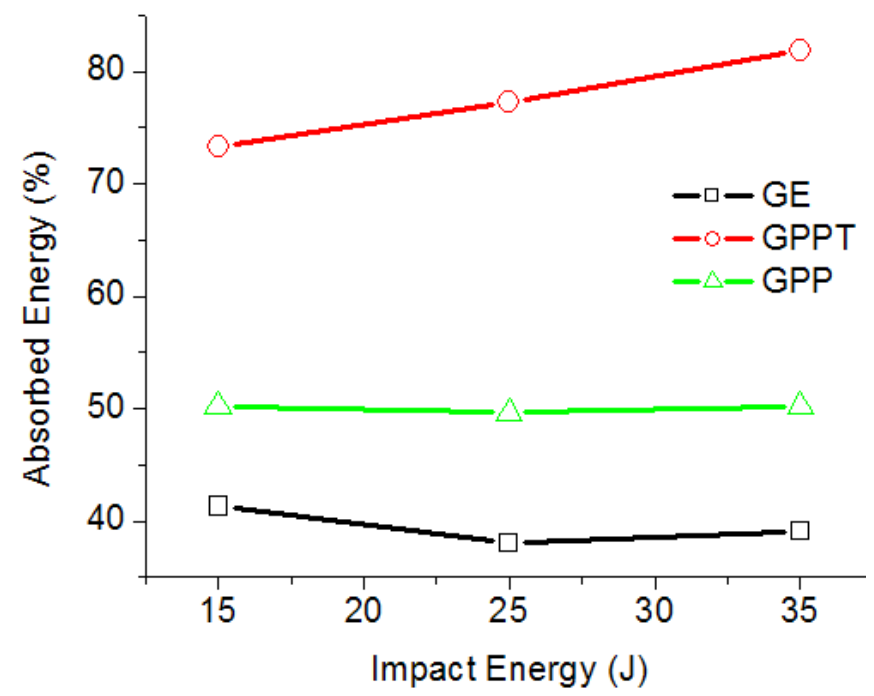

Figure 10 Absorbed energy-impact energy relation of thermoplastic and thermoset composites 
Figure 11 shows that thermoplastic composite had the lowest impact bearing forces in all energy levels even if they have similar glass fibre volume fraction. This result can be explained by the fact that PP has lower strength and modulus than epoxy which directly affect the composite toughness. However, termoset composite (GPP) containing PP fibres had slightly better impact performance than the thermoplastic composites in all energy levels.
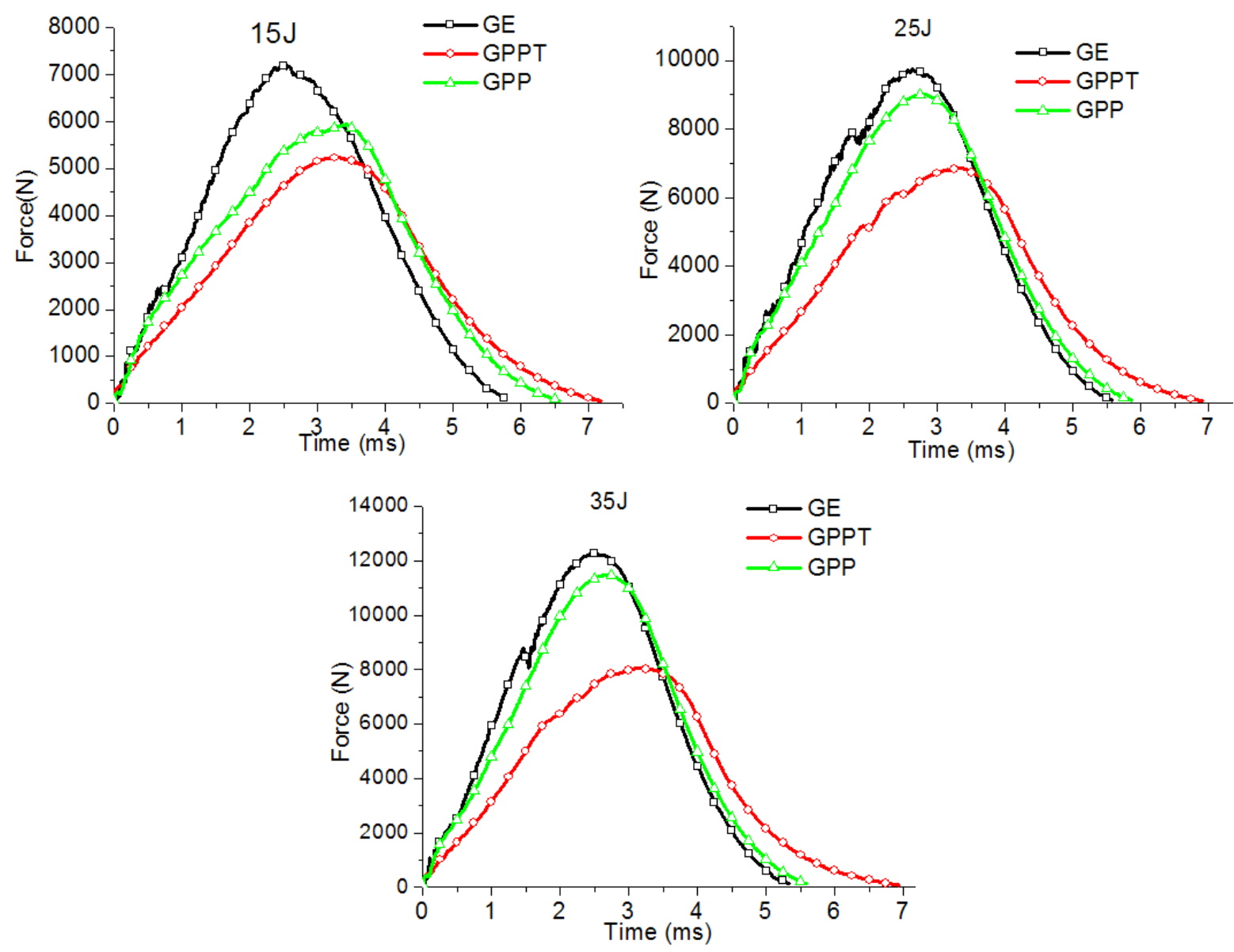

Figure 11 Force-time history of the samples at different impact energy levels (15-35J)

Figure 12 indicates that thermoplastic composite has the highest deformation compared to thermoset samples. This is due to epoxy matrix has better rigidity compared to thermoplastic PP matrix. This deformation behaviour is the reason for higher energy absorption observed in Figure 10. Hybrid composite (GPP) deformation is slightly higher than termoset composite due to containing thermoplastic PP fibres. 

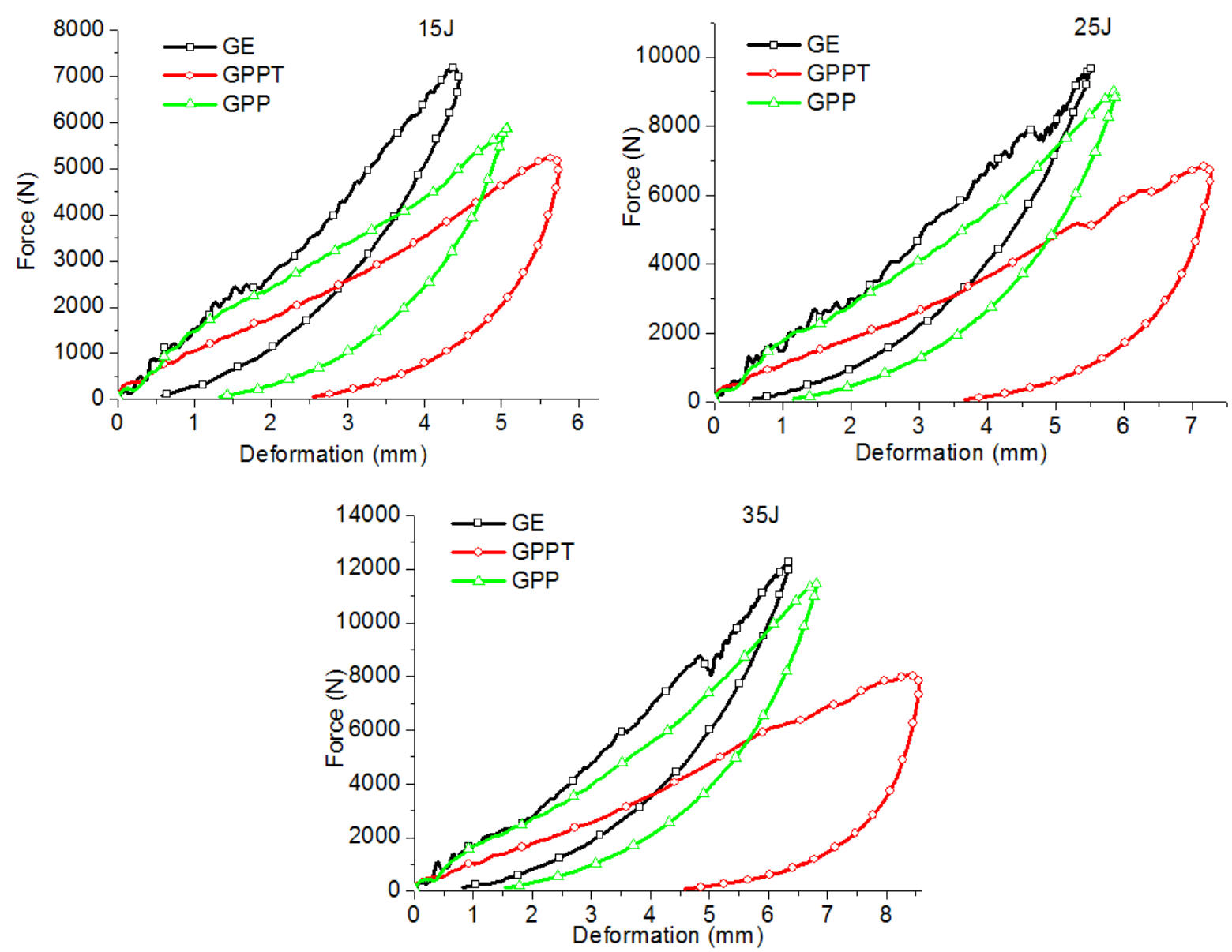

Figure 12 Force-deformation history of the samples at different impact energy levels (15-35J)

\subsection{Compression and CAI tests}

Table 4 presents compression and CAI test results of the composite laminates. GE and GPPT laminates has the highest and lowest compression strength values, respectively. Both GE and GPPT samples have very similar glass fibre volume fractions as in Table 1, but compressive strength of the thermoset laminates is significantly higher than thermoplastic laminate. It seems possible that this result is due to matrix properties whilst epoxy resin is quite rigid and stiffer compared to PP matrices, hence they can endure higher loading forces under the compressive loading.

Table 4. Compression and CAI test results

\begin{tabular}{|c|c|c|c|}
\hline Impact Energy $(J)$ & GE $($ MPa $)$ & GPP $(M P a)$ & GPPT $(\mathrm{MPa})$ \\
\hline 0 & $292.2( \pm 5.6)$ & $139.5( \pm 1.5)$ & $29( \pm 1.2)$ \\
\hline 15 & $125.6( \pm 8.5)$ & $83.6( \pm 1.3)$ & $20( \pm 2.0)$ \\
\hline 25 & $116.5( \pm 4.6)$ & $71.2( \pm 2.5)$ & $18( \pm 1.5)$ \\
\hline 35 & $106.5( \pm 4.9)$ & $62.8( \pm 3.2)$ & $17( \pm 1.7)$ \\
\hline
\end{tabular}

The compression and CAI strength data from Table 4 are plotted in Figure 13 to evaluate the compression strength retention of the laminates after being impacted at different energy levels. Compression strength retention $\left(\sigma_{\mathrm{CAI}} /\right.$ $\left.\sigma_{C}\right)$ is the ratio of the compression strength of the impacted specimens to non-impacted specimens. It can be seen that compression strength decreases with increasing impact energy levels for all laminates. It can also be seen from the same figure that GE laminate retains 36-43\% of its compressive strength after being subjected to 15-35 J impact energies. However, the compressive strength retentions are 45-60\% for GPP and 58-68 \% for GPPT laminates, respectively. This shows that thermoplastic and hybrid laminates have higher compressive strength retention in comparison to the GE laminate, indicating that they are more impact damage tolerant than the glass/epoxy laminates. 


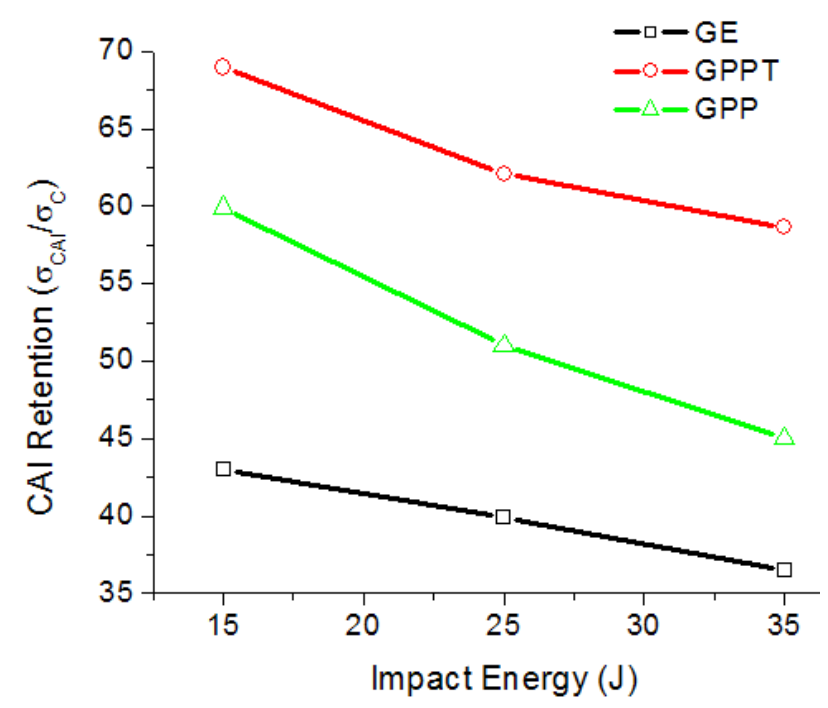

Figure 13 Residual compressive strength of composite laminates at different energy levels

Figure 14 presents the typical failure modes of the GE, GPP, and GPPT under compression loading. It can be seen that the main failure mechanisms are delamination, matrix cracking, fibre breakages, and fibre kinking for GE laminate, while the failure is mainly dominated by the fibre kinking for GPP and GPPT laminates under the compression loading. The bonding between epoxy and glass fibres are strong compared to relatively weak bonding between epoxy and PP fibres. Sudden matrix cracks or delamination happen at high stress points of GE laminates due to strong interface whilst thermoplastic and hybrid laminates gradually fails as the weak bonds. That behaviour also leads GPP and GPPT laminates to have higher CAI retentions compared to GE laminate.

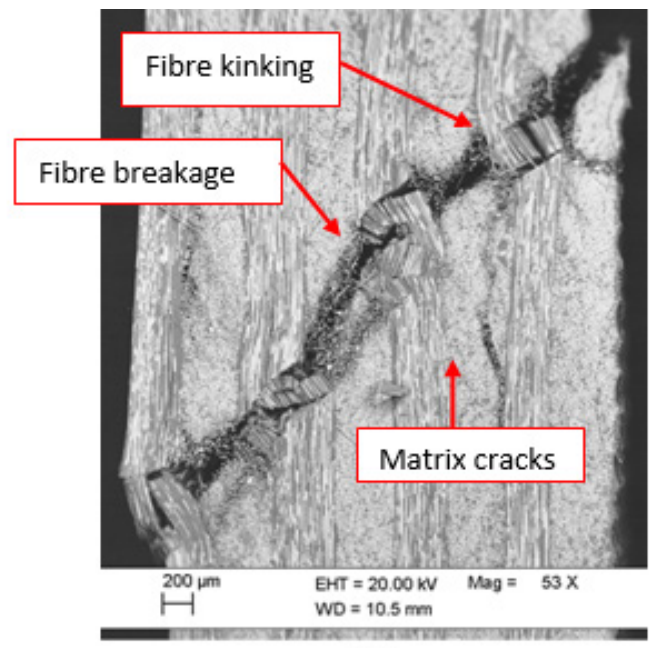

(a)

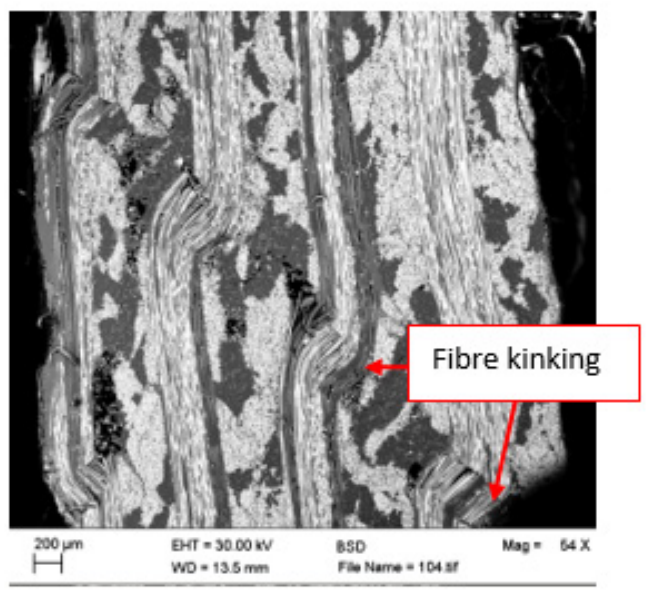

(b)

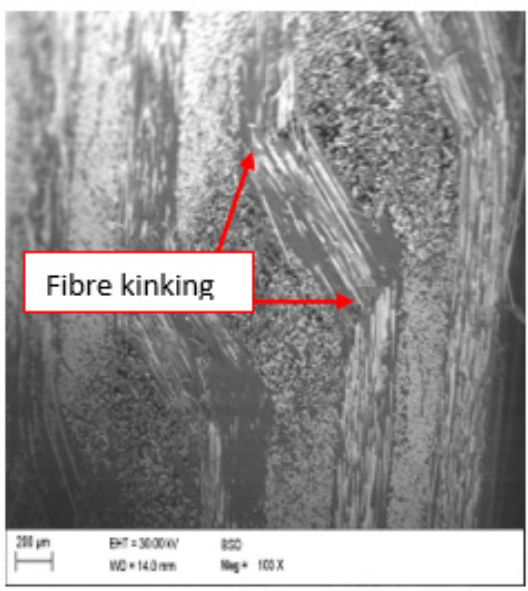

(c)

Figure 14. Typical SEM images of: (a) GE, (b) GPP and (c) GPPT non-impacted samples after the compression test. 


\section{CONCLUSIONS}

The main goal of the study was to determine optimum process parameters (air pressure and overfeeding ratio) of glass/PP commingled yarns and compare impact and damage tolerance performance of commingled thermoplastic composites with thermoset composites. Results showed that optimum process parameters should be decided in order to avoid fibre breakages and better mixing quality. Better glass/PP commingled yarn mixture was achieved when the air pressure is higher.

Impact test results showed that thermoplastic composites absorbed more energy than the thermoset composites due to their plastic deformation and highly extension during impact loading. Thermoplastic composites had significantly lower compression and CAI strength values compared to thermoset composites. However, they had better CAI retention and damage tolerance. Failing mechanism of the thermoplastic and thermoset composites differ from each other due to raw material type and fibre/matrix interface properties.

\section{REFERENCES}

[1] Boria, S., A. Scattina, and G. Belingardi, (2017).Impact behavior of a fully thermoplastic composite. Compos Struct, vol. 167, pp. 63-75.

[2] Sonnenfeld, C., H. Mendil-Jakani, R. Agogue, P. Nunez, and P. Beauchene, (2017).Thermoplastic/thermoset multilayer composites: A way to improve the impact damage tolerance of thermosetting resin matrix composites. Compos Struct, vol. 171, pp. 298-305.

[3] Vendramini, J., C. Bas, G. Merle, P. Boissonnat, and N. D. Alberola, (2000).Commingled poly(butylene terephthalate)/unidirectional glass fiber composites: Influence of the process conditions on the microstructure of poly(butylene terephthalate). Poly Compos, vol. 21, pp. 724-733.

[4] Bernet, N., V. Michaud, P. E. Bourban, and J. A. E. Månson, (2001).Commingled yarn composites for rapid processing of complex shapes. Compos Part A, vol. 32, pp. 1613-1626.

[5] Trudel-Boucher, D., B. Fisa, J. Denault, and P. Gagnon, (2006).Experimental investigation of stamp forming of unconsolidated commingled E-glass/polypropylene fabrics. Compos Sci Technol, vol. 66, pp. 555-570.

[6] Bar, M., A. Das, and R. Alagirusamy, (2017).Studies on flax-polypropylene based low-twist hybrid yarns for thermoplastic composite reinforcement. J of Reinf Plast and Compos, vol. 36, pp. 818-831.

[7] Schafer, J., O. Stolyarov, R. Ali, C. Greb, G. Seide, and T. Gries, (2015).Process-structure relationship of carbon/ polyphenylene sulfide commingled hybrid yarns used for thermoplastic composites. J of Ind Tex, vol. 45, pp. 1661-1673.

[8] Alagirusamy, R., R. Fangueiro, V. Ogale, and N. Padaki, (2006).Hybrid yarns and textile preforming for thermoplastic composites. Text Prog, vol. 38, pp. 1-71.

[9] Mader, E., C. Rothe, and S.-L. Gao, (2007).Commingled yarns of surface nanostructured glass and polypropylene filaments for effective composite properties. J of Mat Sci, vol. 42, pp. 8062-8070.

[10] Mader, E., J. Rausch, and N. Schmidt, (2008).Commingled yarns - processing aspects and tailored surfaces of polypropylene/ glass composites. Compos Part A, vol. 39, pp. 612-623.

[11] Legrand, X., C. Cochrane, and V. Koncar, (2016). A complex shaped-reinforced thermoplastic composite part made of commingled yarns with an integrated sensor. Smart Textiles and their Applications, V. Koncar, Oxford: Woodhead Publishing, pp. 353-374

[12] Hufenbach, W., M. Gude, R. Böhm, and M. Zscheyge, (2011). The effect of temperature on mechanical properties and failure behaviour of hybrid yarn textile-reinforced thermoplastics. Mater Design, vol. 32, pp. 4278-4288.

[13] Long, A. C., C. E. Wilks, and C. D. Rudd, (2001).Experimental characterisation of the consolidation of a commingled glass/ polypropylene composite. Compos Sci and Technol, vol. 61, pp. 1591-1603.

[14] Abounaim, M., O. Diestel, G. offmann, and C. Cherif, (2011).High performance thermoplastic composite from flat knitted multi-layer textile preform using hybrid yarn. Compos Sci and Technol, vol. 71, pp. 511-519.

[15] Wakeman, M. D., P. O. Hagstrand, F. Bonjour, P. E. Bourban, and J. A. E. Månson, (2002).Robotic tow placement for local reinforcement of glass mat thermoplastics (GMTs). Compos Part A, vol. 33, pp. 1199-1208.

[16] Lariviere, D., P. Krawczak, C. Tiberi, and P. Lucas, (2004).Interfacial properties in commingled yarn thermoplastic composites. Part I: Characterization of the fiber/matrix adhesion. Poly Compos, vol. 25, pp. 577-588.

[17] Lee, R. J., (1987).Compression strength of aligned carbon fibre-reinforced thermoplastic laminates. Composites, vol. 18, pp. 35-39.

[18] Chang, I. Y. and J. K. Lees, (1988).Recent development in thermoplastic composites: a review of matrix systems and processing methods. J Thermoplast Compos, vol. 1, pp. 277-296.

[19] Vieille, B., V. M. Casado, and C. Bouvet, (2013).About the impact behavior of woven-ply carbon fiber-reinforced thermoplas- 
tic- and thermosetting-composites: A comparative study. Compos Struct, vol. 101, pp. 9-21.

[20] Touchard-Lagattu, F. and M. C. Lafarie-Frenot, (1996).Damage and inelastic deformation mechanisms in notched thermoset and thermoplastic laminates. Compos Sci and Technol, vol. 56, pp. 557-568.

[21] Erkendirci, Ö. F. and B. Z. Haque, (2012).Quasi-static penetration resistance behavior of glass fiber reinforced thermoplastic composites. Compos Part B, vol. 43, pp. 3391-3405.

[22] Adams, D. O. H. and M. W. Hyert, (1994).Effects of layer waviness on the compression fatigue performance of thermoplastic composite laminates. Inter J of Fatigue, vol. 16, pp. 385-391.

[23] Lachaud, F., B. Lorrain, L. Michel, and R. Barriol, (1998).Experimental and numerical study of delamination caused by local buckling of thermoplastic and thermoset composites. Compos Sci and Technol, vol. 58, pp. 727-733.

[24] Selver, E., P. Potluri, C. Soutis, and P. Hogg, (2015).Healing potential of hybrid materials for structural composites. Compos Struct vol. 122, pp. 57-66.

[25] Selver, E., P. Potluri, P. Hogg, and C. Soutis, (2016).Impact damage tolerance of thermoset composites reinforced with hybrid commingled yarns. Compos Part B, vol. 91, pp. 522-538. 